\title{
KAJIAN PELESTARIAN DAN PEMELIHARAAN BANGUNAN CAGAR BUDAYA DI SURAKARTA
}

\author{
Wahyu Prabowo \\ Program Studi Arsitektur Fakultas Teknik Universitas Tunas Pembangunan Surakarta \\ wahyu.prabowo@lecture.utp.ac.id \\ Abito Bamban Yuuwono \\ Program Studi Arsitektur Fakultas Teknik Universitas Tunas Pembangunan Surakarta \\ Bamban.yuuwono@gmail.com
}

\begin{abstract}
Abstrak
Konservasi merupakan tindakan pelestarian dalam sebuah bangunan cagar budaya. Sasaran tindakan pelestarian dapat berupa bangunan (tangible) maupun non bangunan (intangible). Bangunan cagar budaya yang merupakan objek konservasi mempunyai value yang tinggi dalam proses konservasi, tidak hanya pada objek bangunannya saja namun juga terhadap sejarah, dan peradaban manusia itu sendiri. Bangunan cagar budaya yang tersebar di beberapa wilayah kota Surakarta merupakan bangunan peninggalan masa penjajahan yang mempunyai nilai arsitektur yang penting dalam perjalanan perkembangan ilmu arsitektur di Indonesia. Seiring perkembangan jaman bangunan-bangunan tersebut akan termakan usia dan mengalami degradasi kualitas material atau bahkan struktur bangunan. Namun dalam pelaksanaannya sering kali adanya kekeliuran akibat kurang pahamnya pelaksana dalam menangani tindakan konservasi. Penelitian ini dimaksudkan untuk memberikan informasi bagaimana langkah-langkah dalam kaidah konservasi yang seharusnya, mulai dari mengevaluasi tingkat kerusakan, pendataan hingga langkah perawatan yang diambil.
\end{abstract}

Kata kunci: konservasi, bangunan cagar budaya, keterawatan, degradasi, cagar budaya

\begin{abstract}
Conservation is an act of preservation in a cultural heritage building. The target of conservation measures can be in the form of buildings (tangible) or non-buildings (intangible). Cultural heritage buildings which are objects of conservation have a high value in the conservation process, not only on the object of the building but also on history and human civilization itself. Cultural heritage buildings scattered in several areas of the city of Surakarta are heritage buildings of the colonial period that have important architectural values in the course of the development of architectural science in Indonesia. Along with the development of the era, these buildings will age and experience degradation of the quality of the material or even the structure of the building. However, in its implementation there are often mistakes due to the lack of understanding of the implementers in handling conservation actions. This research is intended to provide information on how the steps in conservation rules should be, starting from evaluating the level of damage, collecting data to taking care steps.
\end{abstract}

Keywords: conservation, cultural heritage building, maintainability, degdradation, cultural heritage 


\section{PENDAHULUAN}

Konservasi merupakan tindakan pelestarian yang dapat diambil dalam rangka menjaga kelestarian bangunan cagar budaya. Seperti yang sudah diatur dalam UU no 11 tahun 2010 tentang cagar budaya, bangunan cagar budaya mempunyai arti penting dalam penguatan identitas budaya bangsa. Melalui bangunan cagar budaya diharapkan dapat menumbuhkan semangat nasionalisme khususnya pada generasi mendatang.

Kota Surakarta yang mempunyai sejarah yang cukup panjang dan dulunya merupakan sebuah kota kerajaan penerus dari dinasti mataram islam, tentunya mempunyai beragam langgam bangunan arsitektur, mulai dari arsitektur tradisional, arsitektur colonial hingga bangunan berlanggam post modern. Kekayaan nilai arsitektur inilah yang selayaknya dapat perhatian khusus mengenai keterawatannya secara menyeluruh. Sehingga kelestarian pada bangunan cagar budaya di Surakarta perlu dijaga mengingat setiap bangunan cagar budaya memiliki nilai yang tinggi, tidak hanya dalam nilai arsitektural, namun juga nilainilai budaya yang terkandung didalamnya.

\section{LANDASAN TEORI}

\subsection{Konservasi}

Secara Umum, konservasi merupakan upaya pelestarian bangunan yang termasuk dalam kategori cagar budaya. Namun, secara konsep konservasi juga dapat berarti konsep proses pengelolaan suatu tempat atau ruang atau obyek agar makna kultural yang terkandung didalamnya terpelihara dengan baik (Saputra, 2013).

Dalam International Council Of Monuments and Site (ICOMOS) tahun 1981 telah disepakati sebuah piagam yang menjadi rujukan setiap arsitek dalam melakukan tindakan konservasi yang disebut piagam Burra Charter, makna pelestarian adalah semua tindakan yang berupa pelestarian yang telah disepakati dalam rumusan piagam tersebut.

Sedangkan menurut sistem perundang-undangan yang diatur di negara kita, yaitu UU no. 11 tahun 2010 tentang cagar budaya, pasal 1 ayat 22, Pelestarian adalah upaya dinamis untuk mempertahankan keberadaan Cagar Budaya dan nilainya dengan cara melindungi, mengembangkan, dan memanfaatkannya. Maka dari itu, didalam Undang-Undang Nomor 11 Tahun 2010 tentang Cagar Budaya memberikan penjelasan mengenai upaya perlindungan secara garis besar terhadap Cagar Budaya yang dilandasi oleh Penyelamatan, Pengamanan, Zonasi, Pemeliharaan, dan Pemugaran Cagar Budaya.

- Penyelamatan

Penyelamatan adalah satu upaya untuk menghindarkan dan/atau menanggulangi Cagar Budaya dari kerusakan, kehancuran, atau kemusnahan.

- Pengamanan

Pengamanan adalah upaya menjaga dan mencegah Cagar Budaya dari ancaman dan/atau gangguan.

- Zonasi

Zonasi adalah penentuan batas-batas keruangan Situs Cagar Budaya dan Kawasan Cagar Budaya sesuai dengan kebutuhan.

- Pemeliharaan 
Pemeliharaan adalah upaya menjaga dan merawat agar kondisi fisik Cagar Budaya tetap lestari

- Pemugaran

Pemugaran adalah upaya pengembalian kondisi fisik Benda Cagar Budaya, Bangunan Cagar Budaya, dan Struktur Cagar Budaya yang rusak sesuai dengan keaslian bahan, bentuk, tata letak, dan/atau teknik pengerjaan untuk memperpanjang usianya.

Adapun kriteria Bangunan cagar Budaya menurut Undang - undang no. 11 tahun 2010, Benda, bangunan, atau struktur dapat diusulkan sebagai Benda Cagar Budaya, Bangunan Cagar Budaya, atau Struktur Cagar Budaya apabila memenuhi kriteria:

a. berusia 50 (lima puluh) tahun atau lebih;

b. mewakili masa gaya paling singkat berusia 50 (lima puluh) tahun;

c. memiliki arti khusus bagi sejarah, ilmu pengetahuan, pendidikan, agama, dan/atau kebudayaan; dan

d. memiliki nilai budaya bagi penguatan kepribadian bangsa.

Menurut Kevin Lynch dalam "The Image of The City"(1960) dalam suatu lingkungan kota, obyek dan lingkup konservasi dapat di golongkan ke beberapa luasan sebagai berikut :

\section{A. Satuan Areal}

Adalah suatu areal dalam kota yang dapat berwujud sub wilayah kota ( bahkan keseluruhan kota itu sendiri sebagai suatu sistem kehidupan ). Ini dapat terjadi pada bagian tertentu kota yang dipandang mempunyai ciri - ciri atau nilai khas kota bersangkutan atau bahkan daerah dimana kota itu berada.

B. Satuan pandangan / visual / landscape Adalah satuan yang dapat mempunyai arti dan peran yang penting bagi suatu kota. Satuan ini berupa aspek visual yang dapat memberi bayangan mental atau image yang khas tentang suatu sesuatu lingkungan kota. Dalam satuan ini ada lima unsur pokok penting yaitu:

1. Jalur (path)

2. Tepian (edges)

3. Kawasan (distric)

4. Pemusatan / simpul (node)

5. Tengeran (landmark)

Termasuk ke dalam golongan ini adalah jaringan fungsional route bersejarah atau jalur angkutan tradisional.

\section{Satuan Fisik}

Adalah satuan yang berujud bangunan, kelompok atau deretan bangunan - bangunan, rangkaian bangunan yang membentuk ruang umum atau dinding jalan, apabila dikehendaki lebih jauh hal ini bisa diperinci sampai kepada unsur - unsur bangunan, baik unsur fungsional, struktur entesis ornemental. Sedangkan secara bentuk umum bentuk konservasi meliputi kota dan desa, distrik, lingkungan perumahan, garis cakrawala wajah jalan dan bangunan.

\section{METODE PENELITIAN}

3.1 Pengumpulan Data

a) Peta Bangunan Cagar Budaya di Surakarta Berdasarkan Surat Keputusan Walikota Surakarta No.646/1-2/1/2013 tentang Penetapan BangunanBangunan dan Kawasan Kuno Bersejarah di 
Kotamadya Daerah Tingkat II Surakarta, terdapat setidaknya 100 bangunan dan kawasan cagar budaya yang tersebar di wilayah kota Surakarta.

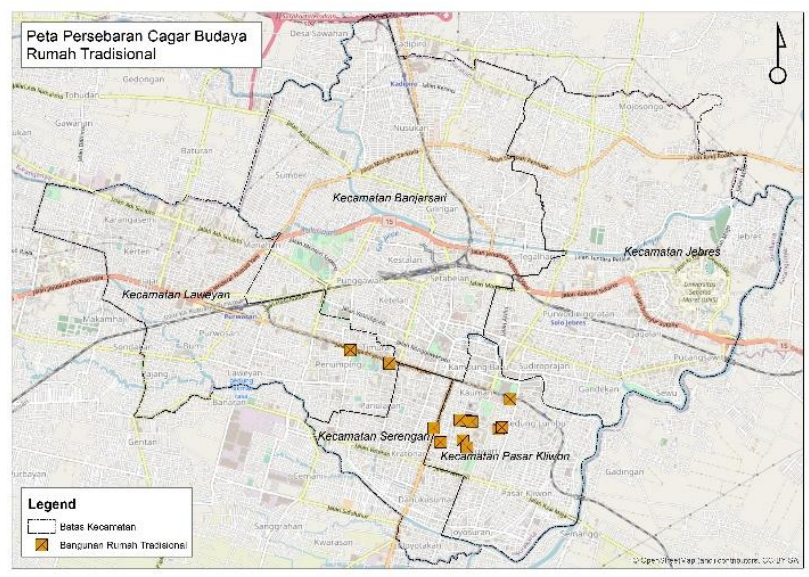

Gambar 1. Peta Persebaran BCB Rumah Tradisional Sumber : Penulis

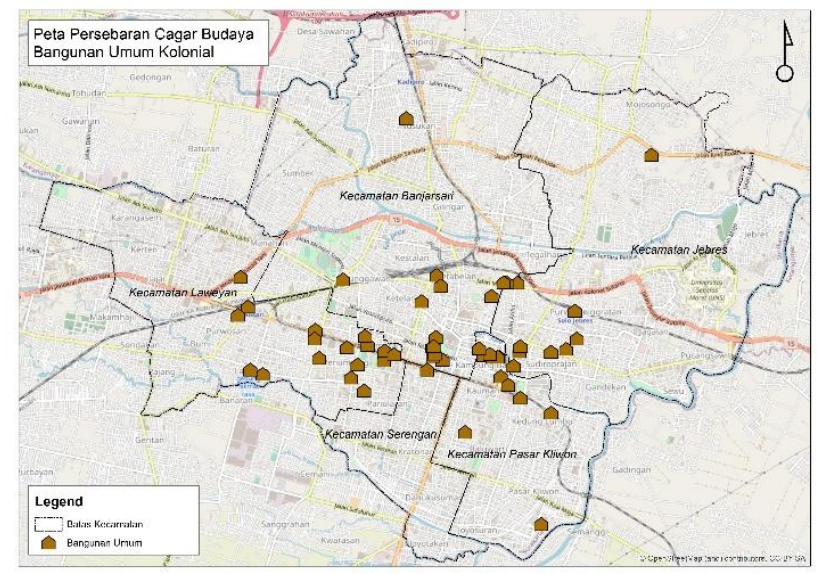

Gambar 2. Peta Persebaran BCB Bangunan Kolonial Sumber : Penulis

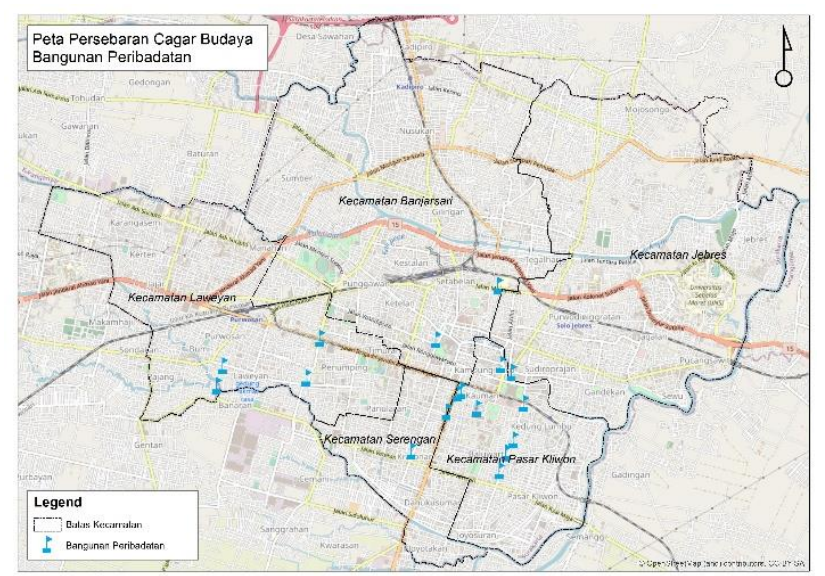

Gambar 3. Peta Persebaran BCB Bangunan Peribadatan

Sumber : Penulis

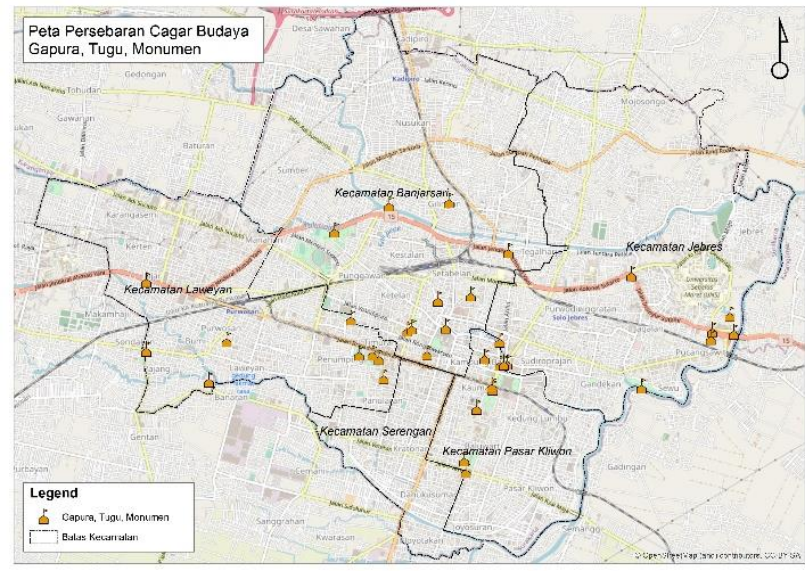

Gambar 4. Peta Persebaran BCB Tugu, Gapura, Monumen

Sumber : Penulis

b) Jenis Bangunan Cagar Budaya di Surakarta Adapun data Bangunan Cagar Budaya berdasarkan Surat Keputusan Wali Kota no. 646/40/I/2014 tentang Penetapan Bangunanbangunan dan Kawasan Kuno Bersejarah di Kotamadya Daerah Tingkat II Surakarta, terbagi dalam enam kategori yaitu Komplek Kawasan, Bangunan Rumah Tradisional, Bangunan Umum Kolonial, Bangunan Peribadatan, Gapura dan Monumen, dan Ruang Terbuka/Taman.

c) Kondisi Bangunan Cagar Budaya di Surakarta Meskipun sudah dilakukan pendataan, kondisi bangunan cagar budaya di kota Surakarta tetap memerlukan perhatian dan perawatan yang intensif dari pemerintah kota Surakarta, hal ini dikarenakan umur bangunan yang sudah tua, faktor iklim dan penyesuaian fungsi pada masa sekarang ini.

Pada Bangunan cagar budaya kelompok rumah tradisional yang mempunyai material yang didominasi material berjenis kayu, mempunyai tingkat kerusakan yang cukup tinggi yang dikarenakan sifat material kayu yang lemah terhadap perubahan cuaca. 


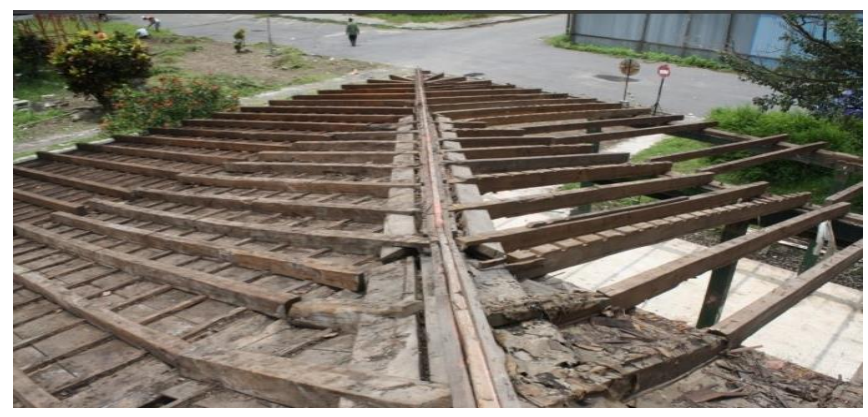

Gambar 5. Jenis Kerusakan Material Kayu Sumber : Indrasana, 2016

Sedangkan pada bangunan cagar budaya kelompok bangunan kolonial kerusakan biasanya terjadi pada dinding dan ornamen dinding yang menjamur atau retak, hal ini dikarenakan teknik pembangunan pada masa bangunan tersebut dibangun belum mengenal teknik sloofing, sehingga memungkinkan terjadinya kapilarisasi pada dinding.

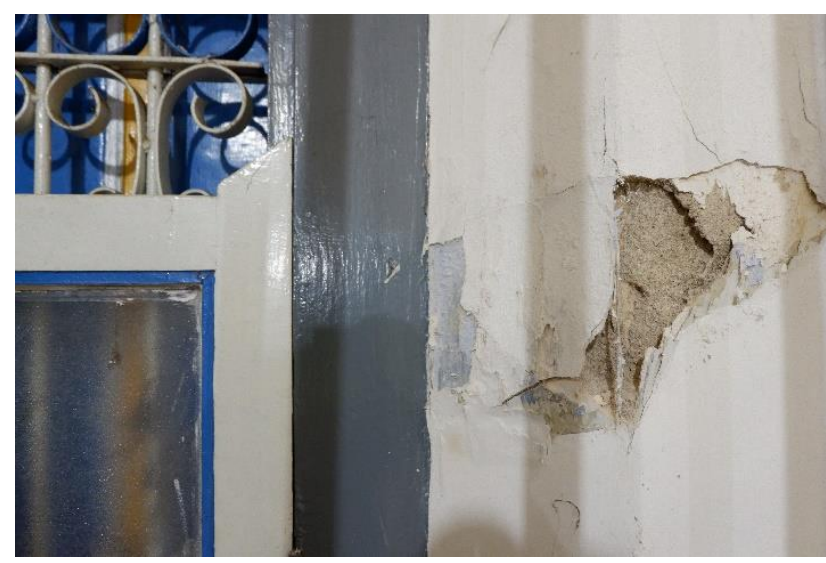

Gambar 6. Jenis Kerusakan pada BCB Bangunan kolonial

Sumber : cv. Djong Indonesia, 2019

\section{ANALISIS}

Berdasarkan data kondisi dan jenis bangunan cagar budaya di Surakarta, analisis yang dapat dilakukan adalah rekomendasi mengenai langkahlangkah perawatan atas kerusakan komponen bangunan yang terjadi. Namun sebelum dilakukan rekomendasi terlebih dahulu dapat dilakukan analisis mengenai tingkat kerusakan supaya dapat ditentukan tindakan apa yang dapat dilakukan.

Tindakan Konservasi pada bangunan cagar budaya dapat dikategorikan dalam beberapa jenis (Sidharta dan Budiharjo, 1989) :

\section{- Preservasi}

Preservasi merpakan tindakan pelestarian suatu tempat persis seperti keadaan aslinya tanpa ada perubahan, termasuk paya mencegah penghacuran.

\section{- Restorasi / Rehabilitasi}

Restorasi merupakan upaya mengembalikan suatu tempat ke keadaan semula dengan menghilangkan tambahan - tambahan dan memasang komponen semula tanpa menggunakan bahan baru.

\section{- Rekonstruksi}

Rekonstruksi adalah upaya mengembalikan suatu tempat semirip mungkin dengan keadaan semula, dengan menggunakan bahan lama maupun bahan baru.

\section{- Adaptasi / Revitalisasi}

Revitalisasi merupakan upaya merubah tempat agar dapat digunakan untuk fungsi yang lebih sesuai. Yang dimaksud dengan fungsi yang lebih sesuai adalah kegunaan yang tidak menuntut perubahan drastis, atau yang hanya memerlukan sedikit dampak minimal.

\section{- Demolisi}

Demolisi adalah penghancuran atau perombakan suatu bangunan cagar budaya yang sudah rusak atau membahayakan. 
Tabel 1. Klasifikasi Tindakan Pada BCB

Sumber : Sidharta dan Budiharjo, 1989

\begin{tabular}{|l|l|l|}
\hline No & Kegiatan & Tingkat Perubahan \\
\hline $\mathbf{1}$ & Konservasi & Tidak Ada \\
\hline $\mathbf{2}$ & Preservasi & $\begin{array}{l}\text { Sedikit/Banyak } \\
\text { Perubahan } \\
\text { (Menyesuaikan) }\end{array}$ \\
\hline 3 & Restorasi & $\begin{array}{l}\text { Banyak/Perubahan } \\
\text { Total }\end{array}$ \\
\hline 4 & Rekonstruksi & Banyak Perubahan \\
\hline 5 & Adaptasi/Revitalisasi & Perubahan Total \\
\hline 6 & Demolisi & \\
\hline
\end{tabular}

Bila melihat klasifikasi tindakan pada bangunan cagar budaya, maka perlu adanya identifikasi dalam menentukan tingkat kepentingan dari bangunan cagar budaya itu sendiri supaya tidak terjadi kekeliruan dalam mengambil tindakan penanganan bangunan cagar budaya. Hal ini juga ditegaskan oleh Sidharta dan Budiharjo dalam Konservasi Lingkungan dan Bangunan Kuno Bersejarah di Surakarta (1989).

Tahapan yang dapat dilakukan dalam mengklasifikasi bangunan cagar budaya antara lain (Sidharta dan Budiharjo,1989) :

1. Pengumpulan data/Inventarisasi

2. Penyusunan/Pengolahan data analisis

3. Pengkajian makna kultural

4. Penentuan prioritas dan peringkat

5. Alternative kebijakan

6. Strategi untuk implementasi

7. Program dan perencanaan

8. Pembiayaan dan pelaksanaan
Setelah diketahui tingkat urgensi dari bangunan cagar budaya maka dapat diambil tindakan perawatan pada objek bangunan cagar budaya.

\subsection{Bangunan Cagar Budaya Rumah}

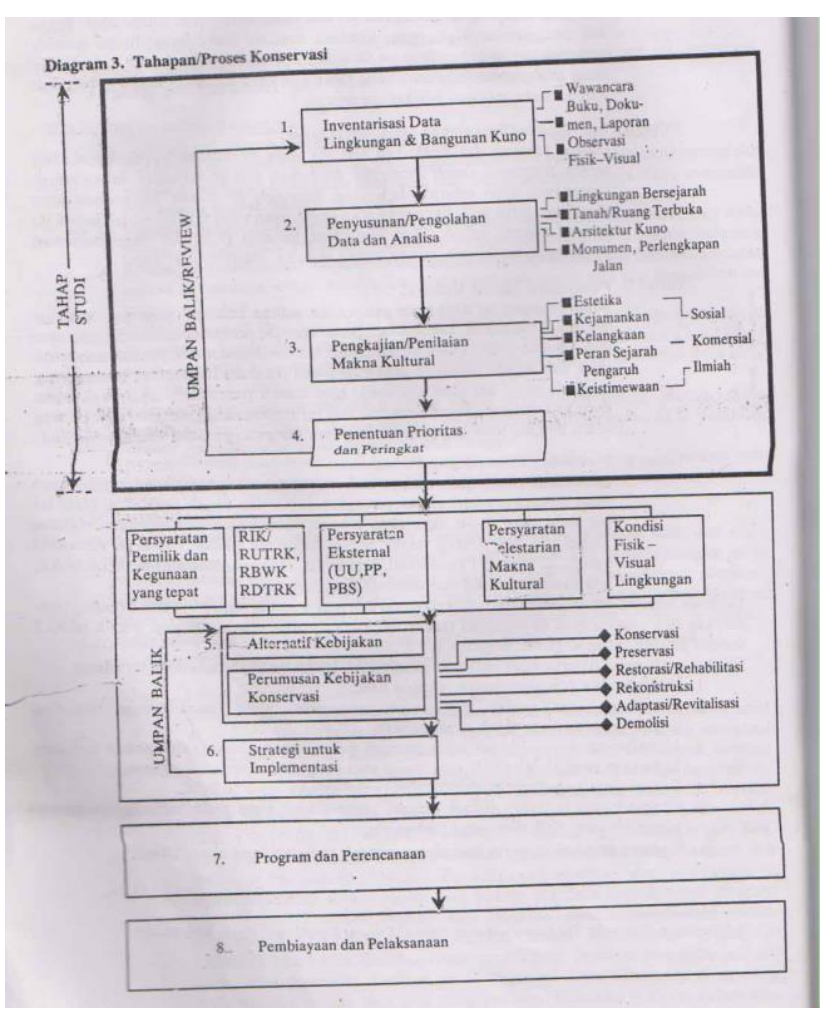

Gambar 7. Tahapan Pelaksanaan Penetapan BCB

Sumber : Sidharta dan Budiharjo,1989

\section{Tradisional}

Bangunan Rumah Tradisional yang notabene merupakan bangunan yang sebagian besar materialnya terbuat dari material alam (kayu, ijuk, bamboo, dll) mempunyai kelemahan dalam menahan faktor alam (iklim, dan serangga), namun demikian usia bangunan tradisional tersebut dapat bertahan dengan rentang usia yang cukup lama. Kerusakan yang terjadi biasanya terjadi pada rusaknya material akibat tergerus faktor alam. 


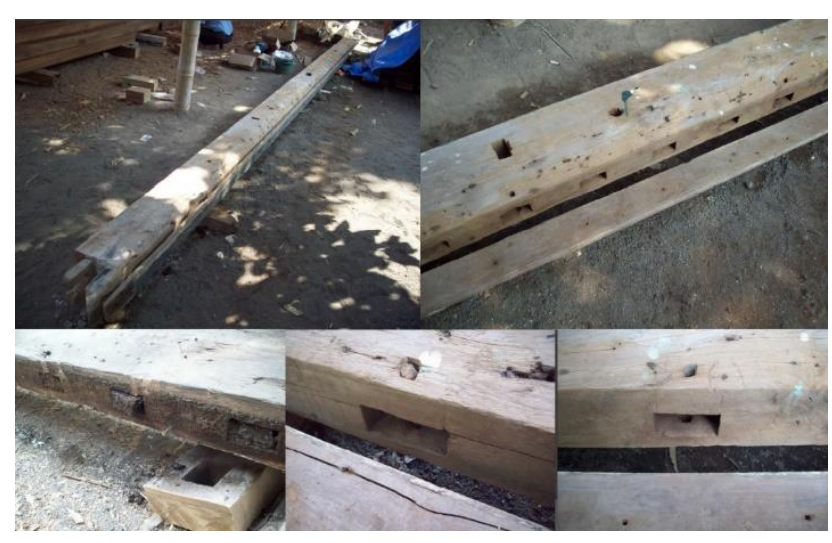

Gambar 8. Kondisi kerusakan kayu

Sumber : Indrasana,2016

Selain kerusakan pada komponennya kerusakan berat yang terjadi pada sebuah bangunan rumah tradisional juga dapat terjadi pada struktur bangunannya yang mengakibatkan bangunan tersebut runtuh, seperti pada salah satu joglo pada Keraton Yogyakarta saat dihantam gempa pada tahun 2006.

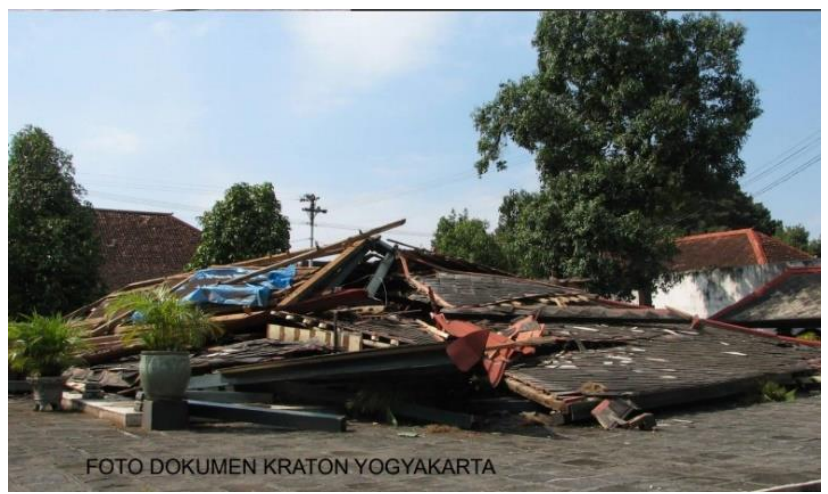

Gambar 9. Bangsal Trajumas Keraton Yogyakarta terdampak gempa 2006

Sumber : Indrasana,2016

\subsection{Bangunan Cagar Budaya Bangunan}

\section{Kolonial}

Bangunan cagar budaya yang bergaya kolonial merupakan bangunan peninggalan pada masa penjajahan bangsa kolonial, dimana dari aspek struktur bangunan sudah menggunakan material batu kali dan batu bata, dan sudah menggunakan finising plester dan aci serta cat, meskipun pada pelaksanaannya menggunakan metode/teknik yang sederhana, tidak ada perkuatan kolom maupun sloof yang membantu memperkuat struktur bangunan, serta plesteran dan acian juga tidak menggunakan material semen seperti bangunan pada masa sekarang. Hal ini dikarenakan pada masa pembangunan bangunan tersebut, memang belum mengenal teknik cor, dan belum mengenal material semen sebagai material penguat. Kerusakan yang terjadi pada bangunan kolonial pun hampir seragam yaitu rusaknya dinding-dinding dan pada bagian atap bangunan.

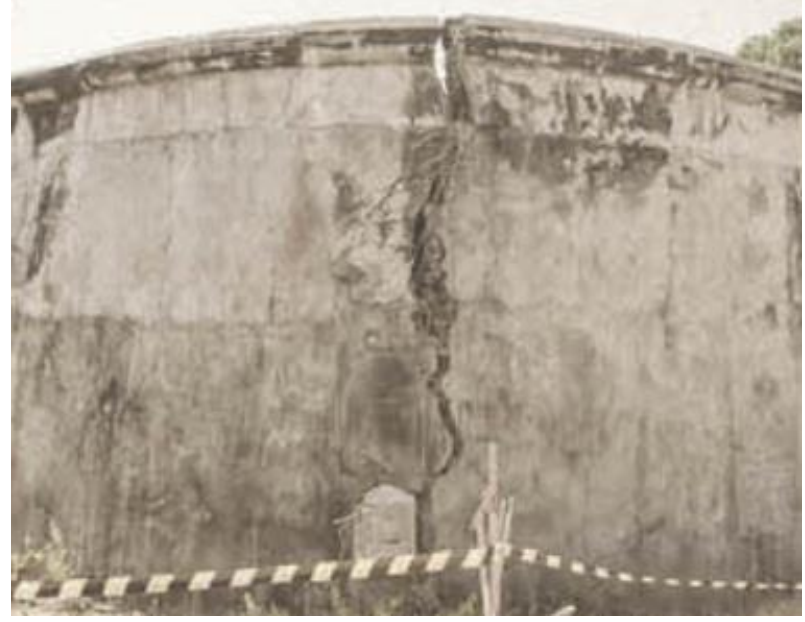

Gambar 10. Kerusakan pada BCB kolonial Sumber : cv. Djong Indonesia, 2019

Pada gambar 11. Terlihat dinding yang retak pada salah satu bagian pada Benteng Vastenburg Surakarta, hal tersebut dikarenakan tidak adanya kolom penguat yang mengikat dinding serta bentangan dinding lepas kolom yang lebar, sehingga menyebabkan dinding tersebut riskan terhadap getaran/goncangan dan beban yang ditanggung oleh dinding tersebut. Selain kerusakan pada struktur, bangunan kolonial juga menghadapi masalah arsitektural yang cukup serius pada dinding yang terkapilarisasi air tanah 
yang naik ke dinding dan menyebabkan dinding menjadi basah. Hal ini terjadi karena pada bangunan kolonial belum mengenal teknik sloofing. Umumnya pondasi yang digunakan pada bangunan kolonial merupakan dinding rolag bata yang jenis materialnya sama dengan yang terpasang pada dindingnya, sehingga, air tanah yang terkandung didalam tanah, dapat masuk menembus pondasi dan menjalar naik hingga ke dinding utama bangunan.

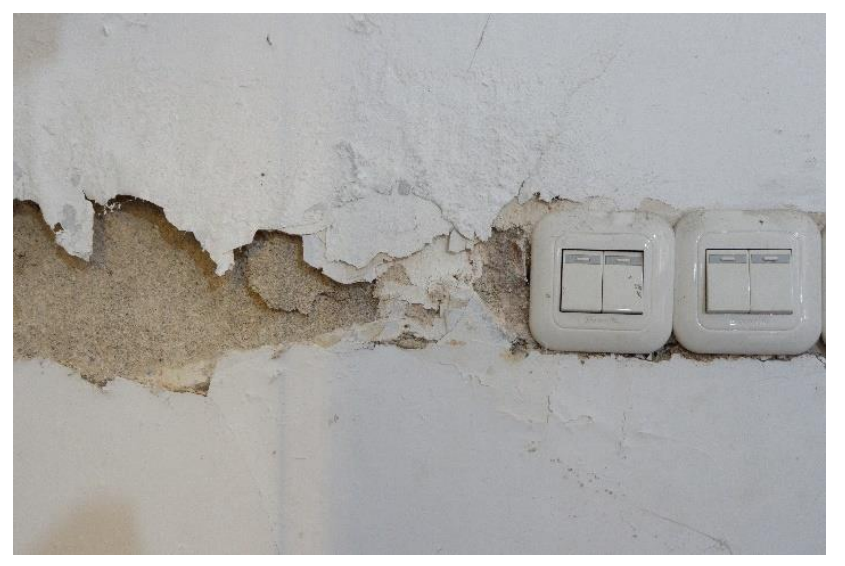

Gambar 11. Dinding BCB kolonial yang terkapiler air Sumber : cv. Djong Indonesia, 2019

Pada gambar 12. Merupakan contoh dinding pada museum Radyapustaka yang terkapilarisasi air, dimana air yang masuk ke dalam dinding dapat memecah plester dan acian, selain karena tidak adanya sloof yang menahan air naik kedalam dinding, plesteran dan acian yang tidak menggunakan semen juga menjadi faktor pecahnya plesteran dan acian.

\subsection{Tindakan Penanganan Konservasi Pada} Bangunan Cagar Budaya.

Tindakan konservasi sudah sewajarnya memperhatikan tingkat keasliannya, usaha yang dilakukan wajib memprioritaskan tampilan, volume bahkan hingga ke material yang digunakan. Menurut Feilden dan Jokilehto (1998), pada dasarnya nilai otentitas bangunan cagar budaya meliputi 4 (empat) aspek utama :

1. Nilai Keaslian Bahan

2. Nilai Keaslian Desain

3. Nilai Keaslian Teknologi Bahan

4. Nilai Keaslian Tata Letak

Namun dalam kasus tertentu, tindakan konservasi mempunyai tingkat toleransi tertentu yang dapat dilakukan. prinsip Reversibilitas (Ganti Ulang) didasarkan pada kesadaran bahwa tindakan konservasi sering kali diputuskan untuk dilakukan meskipun data-data historis sudah dapat diperoleh secara lengkap, namun tindakan ini harus dilakukan untuk menyelamatkan bangunan cagar budaya dari kehancuran.

Kriswandhono dan Pradana (2014), mengungkapkan prinsip reversibilitas atau ganti ulang menjadi acuan utama dimana semua tindakan intervensi terhadap bangunan cagar budaya haruslah :

1. Dapat dikembalikan seperti semula, jika secara teknis memungkinkan

2. Dapat mengakomodasi tindakan intervensi di masa depan jika hal tersebut dilakukan

3. Tidak mengesampingkan kemungkinan akses berikutnya atas semua bukti-bukti berkaitan dengan bangunan tersebut.

Dalam melakukan tindakan perawatan bangunan cagar budaya perlu memperhatikan permasalahan yang ada pada objek cagar budaya tersebut, sehingga perlu dilakukan studi kerusakan bangunan agar dapat ditentukan tindakan apa saja yang dapat dan harus dilakukan. 
Tabel 2. Tabel kerusakan Umum BCB

Sumber : Kriswandhono dan Pradana,2014

\begin{tabular}{|l|l|}
\hline \multicolumn{2}{|l|}{ Tabel Kerusakan Umum Pada Bangunan Cagar Budaya } \\
\hline No & Jenis Kerusakan \\
\hline 1 & Atap Bocor \\
\hline 2 & Serangan Rayap \\
\hline 3 & Air Rembes di Dinding \\
\hline 4 & $\begin{array}{l}\text { Jamur dan pertumbuhan organisme yang tidak } \\
\text { terkendali }\end{array}$ \\
\hline 5 & Pondasi yang tidak kokoh \\
\hline 6 & Naiknya permukaan air dan garam \\
\hline 7 & $\begin{array}{l}\text { Hancurnya Struktur kayu seperti kuda-kuda, lantai } \\
\text { kayu dll. }\end{array}$ \\
\hline 8 & Plesteran bangunan yang rontok atau mengelupas \\
\hline 9 & Mortar yang lepas dan rusak \\
\hline 10 & Cat Mengelupas \\
\hline 11 & $\begin{array}{l}\text { Sistem Pembuangan air dan saluran air hujan yang } \\
\text { rusak }\end{array}$ \\
\hline 12 & Struktur dan Dinding yang retak \\
\hline 13 & $\begin{array}{l}\text { Karat atau korosi yang disebabkan angina laut } \\
\text { atau garam }\end{array}$ \\
\hline 14 & Penanganan Bangunan yang tidak semestinya \\
\hline 15 & $\begin{array}{l}\text { Elemen arsitektur bangunan yang rusak atau } \\
\text { hilang }\end{array}$ \\
\hline 16 & Rusaknya elemen penutup lantai \\
\hline
\end{tabular}

Setelah mengetahui kerusakan apa yang terjadi pada objek bangunan cagar budaya maka dapat dilakukan tindakan perawatan secara kaidah konservasi. Dalam proses perawatan bangunan cagar budaya perlu adanya proses pemulihan arsitektur dimana pemulihan arsitektur yang dimaksud merupakan tahapan kegiatan dalam rangka mengembalikan keaslian bentuk bangunan berdasarkan data yang ada. Kegiatan utamanya berupa pemasangan kembali komponen bangunan baik yang asli maupun pengganti, Pemasangan komponen bangunan asli, didasarkan atas komponen bangunan asli in situ yang dibongkar dengan berpedoman pada sistem registrasi (Indrasana, 2016). Pemulihan arsitektur dilakukan dengan pencermatan data arkeologis. Dari data arkeologis dapat diketahui ada tidaknya perubahan arsitektur, Pengembalian keaslian arsitektur dilakukan sesuai kajian arkeologis.

Indrasana (2016), dalam paparan workshop warisan budaya dan cagar budaya, menyebutkan prosedur penanganan bangunan cagar budaya baik pada bangunan yang runtuh total maupun penanganan sebagian bangunan.

A. Bangunan runtuh total

1. Identifikasi dan pengelompokan material asli berdasarkan fungsi, seperti atap, kerangka atap, kerangka bilik (kolom), dinding, dll.

2. Pemeriksaan bahan layak pakai atau tidak.

3. Pengukuran, pencatatan, dan pendokumentasian setiap komponen bangunan dengan perbandingan skala

4. Anastilosis atau susun coba - untuk menentukan cara-cara penyambungan tiap komponen dan bentuk asli bangunan,

5.Penggambaran ulang bangunan sesuai dengan bentuk aslinya - termasuk setiap detil komponen 
lengkap dengan ukuran dan istilah tiap komponen, pada kondisi eksisting.

6. Penandaan kondisi kerusakan pada gambar dan rencana penggantian komponen.

7.Penyimpanan bahan asli agar terlindung dari kerusakan - dalam hal ini dapat dilakukan pengawetan.

8. Pembuatan gambar rencana renkontruksi dan Desain Rekayasa Detil (Detailed Engineering Design/DED).

9. Pembangunan kembali sesuai dengan gambar DED

B. Bangunan runtuh sebagian

1. Penandaan kerusakan yang terjadi, registrasi,dan pendokumentasian.

2. Pengamanan bagian-bagian yang rusak agar tidak mengalami kerusakan lebih parah.

3. Bagian yang rusak jika memungkinkan dilakukan perkuatan sementara.

4. Melakukan pemeriksaan komponen asli apakah masih layak pakai, perlu perbaikan atau penggantian.

5. Menentukan metode rehabilitasi yang sesuai. Pemilihan teknik, Pemilihan bahan, Prosedur rehabilitasi sesuai karakteristik kerusakan.

6. Rehabilitasi meliputi perkuatan, retrofit (peningkatan kemampuan konstruksi agar sesuai standar) atau rekonstruksi parsial.

\section{KESIMPULAN/RINGKASAN}

Berdasarkan hasil analisis yang dilakukan dapat disimpulkan bahwa:

1. Inventaris Bangunan Cagar Budaya sangat penting untuk dilakukan.
2. Identifikasi tingkat kerusakan sangat diperlukan untuk menentukan tindakan perawatan.

3. Sesuai dengan amanat Undang-undang cagar budaya no. 11 tahun 2010, bangunan cagar budaya merupakan cerminan budaya bangsa sehingga kelestariannya patut dijaga.

4. Kelestarian bangunan cagar budaya dapat memperkaya khasanah arsitektur nusantara yang ada di Indonesia.

5. Secara umum tingkat keterawatan bangunan cagar budaya di Surakarta cukup terawat, terlihat dari keberfungsian bangunanbangunan tersebut dalam mewadahi aktifitas yang ada didalamnya. Karena kerusakan yang terjadi hanya pada bagian finishing dan utilitas bangunan, sedangkan struktur bangunan masih kokoh.

6. Pemahaman mengenai perawatan bangunan cagar budaya pada stakeholder, user, dan perencana/pelaksana sangat penting supaya tindakan pelestarian dapat berjalan dengan baik.

7. Ketepatan langkah penanganan dan ketertiban prosedur dalam menangani bangunan cagar budaya menjadi bagian penting dalam berhasilnya tindakan perawatan.

\section{DAFTAR PUSTAKA}

Sidahrta, Budihardjo E., 1989, Konservasi Lingkungan dan Bangunan Kuno Bersejarah di Surakarta. Gadjah Mada University Press, Yogyakarta.

Kriswandhono A., Pradana N. E.,2014, Konservasi Arsitektural Bangunan Cagar Budaya Kolonial, Institut Konservasi ERMIT, Semarang. 
Lynch K., 1960, The Image Of The City, MIT Press, USA.

Indrasana W., 2016, Pemugaran Bangunan Kayu dalam Workshop Warisan Budaya dan Cagar Budaya, Dinas Kebudayaan DIY-IAAI Komda DIY-Jateng, Yogyakarta.

Feilden B. M, dan Jokilehto, J.,1998, Management Guidelines for World Cultural Heritage Sites, ICCROM, Roma.

CV. Djong Indonesia,2019, Laporan Pelestarian Bangunan-bangunan Bergaya Eropa di Solo, Dinsa Kebudayaan Surakarta.

Undang-undang no. 11 Tahun 2010 Mengenai Bangunan Cagar Budaya.

Surat Keputusan Wali Kota Surakarta no. 646/40/I/2014 tentang Penetapan Bangunanbangunan dan Kawasan Kuno Bersejarah di Kotamadya Daerah Tingkat II Surakarta.

Surat Keputusan Walikota Surakarta No.646/12/1/2013 tentang Penetapan BangunanBangunan dan Kawasan Kuno Bersejarah di Kotamadya Daerah Tingkat II Surakarta.

The Burra Charter, 1981, ICOMOS.

Saputra H., 2013, Kajian Konsep Adaptive Reuse Sebagai Alternatif Aplikasi Konsep Konservasi, Jurnal Arsitektur Universitas Bandar Lampung. 